Canadian

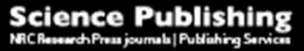

Canadian Journal of Civil Engineering Revue canadienne de génie civil

\title{
Wind-induced shear and torsion in low-rise and medium- rise buildings: Provisions of National Building Code of Canada 2015
}

\begin{tabular}{|r|l|}
\hline Journal: & Canadian Journal of Civil Engineering \\
\hline Manuscript ID & cjce-2017-0107.R1 \\
\hline Danuscript Type: & Article \\
\hline Complete List of Authors: & $\begin{array}{l}\text { Nguyen, Thai Son; Concordia University, Building, Civil and Environmental } \\
\text { Engineering } \\
\text { Stathopoulos, Ted; Concordia University } \\
\text { Tirca, Lucia; Concordia University, Building, Civil and Environmental } \\
\text { Engineering }\end{array}$ \\
\hline $\begin{array}{r}\text { Is the invited manuscript for } \\
\text { consideration in a Special } \\
\text { Issue? : }\end{array}$ & N/A \\
\hline Keyword: & $\begin{array}{l}\text { wind loads, code provisions, shear, torsion, low-rise and medium-rise } \\
\text { buildings }\end{array}$ \\
\hline
\end{tabular}




\title{
Wind-induced shear and torsion in low-rise and medium-rise buildings: Provisions of National Building Code of Canada 2015
}

\author{
Thai Son Nguyen, Ted Stathopoulos, Lucia Tirca
}

T.S. Nguyen. M.A.Sc. student, Department of Building, Civil, and Environmental Engineering, Concordia University, 1455 De Maisonneuve Blvd. West, Montreal, Quebec, Canada, H3G 1M8.

T. Stathopoulos. Professor, Department of Building, Civil, and Environmental Engineering, Concordia University, 1455 De Maisonneuve Blvd. West, Montreal, Quebec, Canada, H3G 1M8.

L. Tirca. 'Associate Professor, Department of Building, Civil, and Environmental Engineering, Concordia University, 1455 De Maisonneuve Blvd. West, Montreal, Quebec, Canada, H3G 1M8.

${ }^{1}$ Corresponding author (e-mail: lucia.tirca@concordia.ca)

Word count: 5982

3

4

15

6

7

8

9

0

1

2

3

4

5

6

7

8

9

0

1




\section{Abstract}

33 This paper discusses the shear and torsion induced in low-rise and medium-rise buildings, according to

34 wind load specifications provided in NBCC 2015. Results from experimental studies, carried out in wind

35 tunnels were compared with corresponding NBCC 2015 provisions under different upstream roughness

36 conditions. These comparisons demonstrated notable discrepancies for the case of torsion in low-rise

37 buildings.

Further, comparisons between the wind load specifications given in NBCC 2015 and ASCE/SEI 7-10 standard were carried out. Following both sets of provisions, wind-induced shear and torsion were computed and compared for five low-rise and medium-rise buildings with the same horizontal dimensions

41 but different heights. Emphasis was directed towards the cases that create maximum shear forces and/or 42 maximum torsions in order to reflect critical design conditions. For low-rise buildings, the ASCE/SEI 74310 and NBCC 2015 yield similar shear coefficients but quite different torsional coefficients; while for 44 medium-rise buildings, clear agreement was found, for both shear and torsion. The diversity of the results 45 is discussed and some suggestions for improvement of code provisions are made. A definition for 46 medium-rise buildings was provided.

\section{Key words: Wind loads, code provisions, shear, torsion, low-rise and medium-rise buildings}

\section{Introduction}

49 Wind loading, especially its torsional effect, plays a critical role on building design. Torsion always 50 occurs even in a perfectly symmetrical building, given that the wind direction toward building wall face is

51 not always perpendicular, and also not distributed uniformly. The equivalent wind force center will not 52 align with the building's center of mass and therefore it will create torsional moments. Moreover, most 53 buildings have inherent eccentricities between the center of mass and that of rigidity. The impacts that 54 wind-induced torsion could cause depend on several conditions, such as: building location, geometry, 55 lateral force-resisting system and its material. Torsion can significantly increase the shear loads applied 
56

57

on the lateral force-resisting system comparing to the conventional loading method, which only considers wind-induced shear. Therefore, the wind torsional effects cannot be neglected and need to be appropriately evaluated by code computations.

According to NBCC 2015, low-rise buildings are those with $H \leq 20 \mathrm{~m}$ and $H / D_{s}<1$, where $H$ is the building height and $D_{s}$ is the smaller plan dimension. All buildings with $H>20 \mathrm{~m}$ and $H / D_{s} \geq 1$ are classified as high-rise buildings which may be dynamically sensitive or very dynamically sensitive. A building is classified as dynamically sensitive if its lowest natural frequency is less than $1.0 \mathrm{~Hz}$ and greater than $0.25 \mathrm{~Hz}$, its height is greater than $60 \mathrm{~m}$, or its height is greater than 4 times its minimum effective width, $w$. For a rectangular building the minimum effective width is equal to $D_{s}$. A building having its lowest natural frequency $\leq 0.25 \mathrm{~Hz}$ or its height more than 6 times its minimum effective width is classified as very dynamically sensitive. However, in the current code, there is not a definition for medium-rise buildings. In this study, a medium-rise building is defined as a building with $\mathrm{H}$ greater than $20 \mathrm{~m}$ and less than or equal to $60 \mathrm{~m}$ or $1 \leq H / D_{s} \leq 4$.

To investigate the most critical impacts of wind load on medium-rise buildings, along with the conventional full loading case (Case A), three different partial loading cases have been introduced in NBCC 2015 (Cases B, C, D) as shown in Fig. 1. However, several issues have been encountered in the process of determining torsions in load Cases B and D. Firstly, in the torsional load cases, the uniformly distributed wind forces acting on the building are partly reduced (in terms of both magnitude and tributary area) in one or both of the principal directions in order to create the most severe torsional effects on buildings. These effects, along with the effect from the full loading case, are then compared to conclude the most critical scenario in terms of shear and torsional effects. While the subtracted load magnitude is mentioned explicitly in the code, the tributary area remains unclear for load Cases B and D and this creates ambiguities among the NBCC users. Secondly, these load cases do not apply to low-rise buildings, for which the torsional effects are presumably covered by the stipulations of Fig. 2, in which two load Cases, A and B, are specified. However, Stathopoulos et al. (2013) have shown that these provisions may not be adequate for torsion. Although these issues are known for a while, little research 
82 has been carried out to address them systematically in order to modify the Canadian wind load 83 specifications accordingly.

Other wind codes and standards address torsional loads differently. For instance, the American

85 standard ASCE/SEI 7-10 specifies that, for low-rise buildings, besides applying higher wind loads on wall corners, only $25 \%$ of the full design wind pressure is placed on half of the wall face to account for torsional effects. For other buildings, eccentricities and torsion moments are given explicitly by formulas with wind loads applying on full tributary areas for all load cases. In Eurocode (EN 1991-1-4 2005), the torsional effects are taken into account by changing the uniformly distributed wind load in the windward direction represented by rectangular loading to inclined triangular loading while keeping the same load on the leeward wall face. It also regulates that in some cases, wind loads in locations that create beneficial impacts should be completely removed, but this regulation is not very clear for the users. The Australian/ New Zealand building code (AS/NZS 1170.2 2011) fully neglects the wind-induced torsion for low-rise and medium-rise buildings whereas for high-rise buildings defined by height $>70.0 \mathrm{~m}$, an eccentricity of $20 \%$ of the width of windward wall is considered to account for torsion.

\section{NBCC 2015 provisions for wind loads on buildings}

\subsection{General}

The objectives of this study are twofold: i) recommend an approach for determining the appropriate tributary areas needed to generate the maximum torsion effects in Case B and Case D recommended in NBCC 2015 for high-rise buildings and applied herein also for medium-rise buildings and ii) examine the adequacy of wind loads (base shear and torsion) determined by the NBCC 2015 through comparisons with results from previous studies and ASCE/SEI 7-10 standard provisions.

The full wind external pressure in NBCC 2015 is given by:

$$
p=I_{w} q C_{e} C_{t} C_{g} C_{p}
$$

where $I_{W}$ is the importance factor for wind load; $q$ is the reference velocity pressure; $C_{e}, C_{t}$ and $C_{g}$ are the exposure, topographic, and gust effect factor; and $C_{p}$ is the external pressure coefficient. After the wind 
106

107

108

109

110

pressures are acquired they are multiplied by the corresponding projected/ tributary area to attain the external wind forces acting on the building wall faces. The wind loads are computed for each floor before being summed up to obtain the base shear. The process is carried out for two orthogonal directions. Torsion moments are formed by the unbalance of wind pressures on building wall faces, as specified in the partial loading cases.

For buildings higher than $60 \mathrm{~m}$ or the height to minimum effective width ratios $>4.0$ or with lowest natural frequency lower than 1.0, the dynamic procedure should be applied. The same provisions to static procedure, including the partial loading cases, shall be followed, except that the exposure factor, $C_{e}$ and the gust factor, $C_{g}$ are evaluated differently (NBCC 2015). The lowest natural frequency of the building is recommended to be computed by the following equation:

$$
f_{n}=\frac{1}{2 \pi} \sqrt{\frac{\sum_{i=1}^{N} F_{i} \frac{x_{i}}{x_{N}}}{x_{N} \sum_{i=1}^{N} M_{i}\left(\frac{x_{i}}{x_{N}}\right)^{2}}}
$$

116 where $N$ is the number of stories; $F_{\mathrm{i},} M_{i}$ are the lateral load and floor mass at level $\mathrm{i}^{\text {th }} ; x_{i}$ and $x_{N}$ are the 117 horizontal deflections of floor at level $i$ and $N$, respectively.

In some cases, partial loadings can cause severe effects. As already mentioned for high-rise/ medium-rise buildings, four load cases are presented in NBCC 2015 (A, B, C and D). While Cases A and C focus on the effect of shear force, Cases B and D emphasize the torsional impact on structures. The 121 conventional loading method is followed by the Case A when $100 \%$ of wind forces are loaded separately 122 in each principal axis. Clearly, this case is found to produce the maximum base shear. The wind loads 123 with the same magnitude are applied on parts of the wall faces to create additional torsions in load Case 124 B. The tributary area of the wind pressure acting on a given story wall face is given as a product of the 125 height of the story under consideration and the horizontal distribution length of the wind load. However, 126 the latter is not provided explicitly by NBCC 2015, which may lead practitioners to different tributary 127 areas, and therefore, different wind forces, and potential false assessments of the torsional effects of wind 128 loads on buildings. Thus, this issue requires clarification. Wind blowing diagonally to the walls can be 
129 illustrated equivalently by simultaneous reduced forces. For instance, $75 \%$ of full load are applied

130 simultaneously on both wall faces to create Case C. In Case D, 50\% of those in Case C are partly 131 subtracted from wall faces. Similar to Case B, the wind projected area in Case D is just mentioned as 132 "reduced from part of projected area". The term "part" needs to be clarified as it raises questions among 133 the code users.

Two load cases are mentioned in NBCC 2015 for low-rise buildings, namely load Case A and Case B, which simulate wind loads applying perpendicular and parallel to the ridge of a building, respectively. As specified in Case B, when acting parallel to the building's ridge, wind forces also create impacts to both sides of the buildings. Also, the wind pressures are different on opposite sides of the building roof. However, the current study only considers buildings with flat roofs. Therefore, these effects can be neglected because the across-wind forces on opposite wall faces eliminate each other. As a result, the two load cases merge into a single case. The wind pressures are defined as shown in Eq. (1). However, for low-rise buildings, instead of determining the external pressure coefficient, $C_{p}$, and gust effect factor, $C_{g}$ separately as in the case of medium-rise buildings, the external peak composite pressuregust coefficients, $C_{p} C_{g}$ are obtained based on the positions of wind loads applied on the wall faces. The other parameters $\left(I_{w}, q, C_{e}\right)$ are computed in the same way as for high-rise/ medium-rise buildings.

\subsection{Torsional load case for medium-rise buildings}

146 In medium-rise buildings, torsional effects are computed by considering the two partial loading cases:

147 Case B and Case D. The tributary area of wind load that could produce the maximum torsions are recommended by using a mathematical method. The method of determining maximum torsion in Case D is illustrated in Fig. 3. The same approach can be adopted to determine the maximum torsion in load Case $\mathrm{B}$, as it is a simplified case of Case D.

As previously mentioned, the tributary area of the uniformly distributed wind force acting on a

152 given story is given as: $A=l \times h$, where $h$ is the height of the story under consideration, and $l$ is the 153 horizontal distribution length of the wind load. According to NBCC 2015, the horizontal distribution 
154 length (mentioned as $a, b, c$ and $d$ in Fig. 3) are unknown. These values need to be determined so that the 155 corresponding wind forces applied simultaneously in both wall faces of the building create a maximum 156 moment $M$, which is the summation of the moments induced by wind forces in each direction:

$$
M=M_{x}+M_{y}
$$

157 Herein, $M$ is maximum when $M_{x}$ and $M_{y}$ reach their highest values. The moment due to wind load along 158 the N-S direction is given by:

$$
M_{x}=p_{2} b h e_{2}-p_{1} a h e_{1}
$$

where $p_{1}$ and $p_{2}$ are uniform wind forces acting on the wall faces in the N-S direction; $e_{1}$ and $e_{2}$ are the eccentricities of $p_{1}$ and $p_{2}$, respectively; and $a$ and $b$ are the horizontal distribution length of $p_{1}$ and $p_{2}$, respectively. substituting these parameters in Eq. (4), it results:

$$
\begin{array}{rl}
M_{x}=p_{2} & b h\left(\frac{L}{2}-\frac{b}{2}\right)-p_{1} a h\left(\frac{L}{2}-\frac{a}{2}\right)=p_{2} b h \frac{L}{2}-p_{2} h \frac{b^{2}}{2}-p_{1} a h \frac{L}{2}+p_{1} h \frac{a^{2}}{2} \\
= & p_{2} b h \frac{L}{2}-p_{2} h \frac{b^{2}}{2}-p_{1}(L-b) h \frac{L}{2}+p_{1} h \frac{(L-b)^{2}}{2} \\
= & p_{2} b h \frac{L}{2}-p_{2} h \frac{b^{2}}{2}-p_{1} h \frac{L^{2}}{2}+p_{1} b h \frac{L}{2}+p_{1} h \frac{b^{2}+L^{2}-2 L b}{2} \\
= & p_{1} h \frac{b^{2}}{2}-p_{2} h \frac{b^{2}}{2}+p_{2} b h \frac{L}{2}-p_{1} b h \frac{L}{2} \\
= & \left(\frac{p_{1}}{2}-\frac{p_{2}}{2}\right) b^{2} h+\left(\frac{p_{2} L}{2}-\frac{p_{1} L}{2}\right) b h
\end{array}
$$

164 As can be seen, $M_{x}$ is a quadratic function of variable $b$. This function reaches its maximum value when 165 its differentiation with respect to $b$ is equal to zero, i.e.:

$$
\begin{aligned}
& M_{x}^{\prime}=\left(p_{1}-p_{2}\right) b h+0.5\left(p_{2}-p_{1}\right) L h=0 \\
& \Leftrightarrow b=\frac{L}{2}
\end{aligned}
$$


Therefore, the maximum torsion due to wind along the N-S direction occurs at $b=a=L / 2$. Similarly, $M_{y}$ is maximum when $c=d=B / 2$.

Applying the same procedure, the torsions in Case B are maximum when pressures are applied on half of the wall faces. The maximum torsion effect is chosen by comparing the results of Case B and Case D. The most critical shear effect comes from the maximum value of Case A and Case C.

\subsection{Torsional load case for low-rise buildings}

In terms of low-rise buildings, only two Cases, namely A and B, are present in NBCC 2015, when torsion is caused by a higher concentration of wind loads in each wall face corner. As opposed to partial loading cases for medium-rise buildings, the tributary areas of wind forces are stated explicitly for low-rise buildings as exhibited in Fig. 4. Torsion moment for these cases is computed by the following formula:

$$
M=\left(p_{1}+p_{4}\right) e_{1}(L-y) h-\left(p_{1 E}+p_{4 E}\right) e_{1 E} y h
$$

Herein, $y$ is the width of the end-zone computed as the greater of $6 \mathrm{~m}$ and $2 z$, where $z$ is the lesser of $10 \%$ of the least horizontal dimension or $40 \%$ of height, $H$, but not less than $4 \%$ of the least horizontal dimension or $1.0 \mathrm{~m}$.

\section{Comparisons between NBCC 2015 and experimental results from previous studies}

\subsection{Selection of experimental studies from the literature}

The first comparisons are made between the wind loads computed by NBCC 2015 and those from wind tunnel tests collected from four previous studies regarding both low-rise and medium-rise buildings under different exposures. The four previous studies chosen are: Isyumov and Case (2000), Keast et al. (2012), Tamura et al. (2003), and Stathopoulos et al. (2013). The configurations of buildings tested in these studies are shown in Table 1, where they are also grouped into low-rise and medium-rise categories. Some assumptions have been made due to the lack of information that is essential for the application of the NBCC 2015 provisions. For instance, the studied buildings are steel structures and the lateral forceresisting systems consist of limited ductility concentrically braced frames. The two largest shear in the 
189 two principal wall face directions along with the maximum torsion are selected in each building 190 considering all load cases, for both low-rise and medium-rise buildings in open and urban-terrain areas.

191 Four partial loading cases are considered for medium-rise buildings. For the torsional load Cases B and 192 D, the tributary area has been determined as recommended previously in Eq. (6). For low-rise buildings, 193 shear and torsion are attained following Cases A and B as prescribed in Fig. 4. Based on building 194 properties (geometry, dimensions, and natural frequency), some are computed by the static procedure, 195 while others follow the dynamic procedure. Detailed information about computational procedure for all 196 buildings is provided in Table 2. It is noted that $w$ parameter provided in Table 2 is the minimum effective 197 width. For the current study, the ETABS software (CSI 2016) was used to compute the building's natural 198 frequency.

\section{$199 \quad$ 3.2 Shear and torsional coefficients}

200 In order to compare results between studies with different building locations and exposure terrains, 201 maximum base shear forces and torsions are normalized to obtain the shear and torsional coefficients, 202 defined as follows:

$$
\begin{gathered}
C_{V}=\frac{V}{q_{H} B L} \\
C_{T}=\frac{T}{q_{H} B^{2} L} \\
q_{H}=q C_{e}
\end{gathered}
$$

203 where $C_{V}$ and $C_{T}$ are shear and torsional coefficients; $V$ and $T$ are the base shear and torsion; $B$ and $L$ are

204 the shorter and longer horizontal dimensions of the building; $q_{H}$ is the mean dynamic wind pressure at 205 roof height $H ; q$ is the reference velocity pressure based on the mean hourly wind speed; and $C_{e}$ is the 206 exposure factor. 
Due to the diversity of coefficient definitions among the past studies, all coefficients given have

all been transformed to be consistent with those of the current study. The transformation equations used for each study are provided in Table 3 .

\subsection{Results and Discussions}

In this section, the comparisons between the shear and torsional coefficients resulted from wind tunnel tests and the corresponding code results are depicted in graphs where the vertical axis shows shear or torsional coefficients from wind tunnel tests, while those from NBCC 2015 are placed on the horizontal axis. Each pair of results (experimental and code results) is represented by a point. The closer the point is to the balance line (form an angle of $45^{\circ}$ with the axes), the better is the agreement between code provisions and experimental results.

Figure 5 compares the torsional coefficients in two separate categories namely low-rise and medium-rise buildings. Clearly, the NBCC 2015 greatly underestimates torsional effects on low-rise buildings through all cases. Thus, all points shown in the graph for low-rise buildings are at noticeable distances to the balance line (experimental results are 6 to 10 times higher than those from NBCC 2015). Moreover, the underestimation in torsional effects of NBCC 2015 for low-rise buildings can be witnessed through the case of the two buildings of Stathopoulos et al. (2013). These two buildings are $20.0 \mathrm{~m}$ high (low-rise building) and $30.0 \mathrm{~m}$ high (medium-rise building) and have the same horizontal dimensions and exposure conditions. According to the Canadian code computations, the torsional coefficient increases ten times from 0.024 (20.0 $\mathrm{m}$ - low-rise building) to 0.26 (30.0 $\mathrm{m}$ - medium-rise building). The values from the wind tunnel tests are 0.15 and 0.27 , correspondingly, making a smaller jump of about 1.8 times. For medium-rise buildings, all studies give similar results with the computations from NBCC 2015, except for the case of the building of Tamura et al. (2003) in urban-terrain area where the results are overestimated. Furthermore, the NBCC 2015 have resulted slightly higher torsional coefficient values.

In conclusion, torsional effects on low-rise buildings are not assessed properly by NBCC 2015. Conversely, good assessments have been shown in medium-rise buildings with the application of partial 
232 loading. Therefore, it was decided to test the effectiveness of the medium-rise building methodology for 233 low-rise buildings although, according to NBCC 2015, partial loading cases are not required for them. 234 Cases B and D are applied to all the low-rise buildings of the previous studies to obtain the maximum 235 torsions. The torsional coefficients resulted from this process are exhibited in Fig. 6. The abbreviation 236 "PL" in the figure implies the results from the partial loading Cases B and D. Much better results are 237 shown clearly as the torsional coefficients of the code are much closer to those provided by the 238 experimental studies. Discrepancies decrease to only within 1.5 times. Evidently, if partial loading cases 239 are applied as for the case of medium-rise buildings, the torsional effects on low-rise buildings can be 240 estimated more appropriately, although somewhat underestimated.

Figure 7 presents the comparisons between shear coefficients obtained from NBCC 2015 and 242 wind tunnel tests. The shear coefficients are computed in two principal wind directions: N-S and W-E. In 243 general, good similarities between the code computations and the test results are present. For low-rise 244 buildings, four out of six shear coefficients computed from NBCC 2015 are nearly equal to the experimental coefficients. However, an underestimating trend is demonstrated. Additionally, shear coefficients adequacy decrease in the N-S direction (the longer wall face). For medium-rise buildings,

247 there is an excellent agreement in seven out of eight cases. The best agreement is found in the results of 248 Stathopoulos et al. (2013) for both terrains (only roughly 1\% difference). The largest difference found 249 was approximately $16 \%$, in the case of the $60.0 \mathrm{~m}$ high building in the study of Keast et al. (2012), which 250 is also the highest building among all studies.

In brief, with the exception of the underestimated torsional effects for low-rise buildings, the 252 NBCC 2015 seem to evaluate the impact of wind loads on low-rise (shear effects) and medium-rise 253 buildings adequately. Potential remedies can be taken in the case of torsional effects on low-rise buildings 254 by applying the partial loading cases, similar to the case of medium-rise buildings.

\subsection{Discussion on the discrepancies between results from NBCC 2015 and wind tunnel tests}


256 The underestimation in torsions for low-rise buildings is due to the fact that the code does not take partial

257 loading into account. As can be seen in Fig. 2, the higher wind pressures (the factor that produces the 258 torsional effects) are only placed in a small area $y \times h$ in the building's corners, where $y$ is the maximum 259 of $6 \mathrm{~m}$ or $2 z$. This value, in most cases, is not comparable to half of the wall dimension perpendicular to 260 wind directions, which is shown in Eq. (6) to produce the maximum torsion. This inappropriate pressure 261 distribution also results in small shear coefficients, as illustrated in Fig. 7.

262 Discrepancies between shear and torsional coefficients in medium-rise buildings provided by 263 NBCC 2015, as shown in Figs. 5, 6 and 7, may be attributed to the lowest natural frequency of the 264 building, $f_{n}$. As shown in Table 1, the dynamic procedure was applied for all medium-rise buildings. 265 Wind loads determined by dynamic procedure are controlled by the building natural frequency, which may be not similar between buildings in the current study and the previous studies due to the differences

267 in building materials and lateral force-resisting systems. The assumptions made in the current study may 268 result in different building material, lateral force-resisting system, and damping ratios to the past studies.

269 As a result, dissimilar natural frequencies between buildings occur and directly affect the values of the 270 size reduction factor $s$, and gust energy ratio at the natural frequency of the structure $F$, and consequently 271 the gust factor $C_{g}$ as shown below:

$$
\begin{aligned}
& C_{g}=1+g_{p} \sqrt{\frac{K}{C_{e H}}\left(B+\frac{s F}{\beta}\right)} \\
& s=\frac{\pi}{3}\left[\frac{1}{1+\frac{8 f_{n} H}{3 V_{H}}}\right]\left[\frac{1}{1+\frac{10 f_{n} w}{V_{H}}}\right] \\
& F=\frac{\left(1220 f_{n} / V_{H}\right)^{2}}{\left[1+\left(1220 f_{n} / V_{H}\right)^{2}\right]^{4 / 3}}
\end{aligned}
$$

272 Herein, $g_{p}$ is the peak factor, $K$ is a factor related to the surface roughness coefficient of the terrain, $C_{e H}$ is

273 the exposure factor evaluated at the top of the building, $B$ is the background turbulence factor, $\beta$ is the 274 critical damping ratio in the along-wind direction, $f_{n}$ is the fundamental frequency, $H$ is the height of the 
275 building, $V_{H}$ is the mean wind speed at the top of the structure, and $w$ is the effective width of windward 276 face of the building.

Computations with steel and concrete structures with different types of lateral force-resisting system were carried out to examine the differences between their wind-induced shears and torsions. The $30.0 \mathrm{~m}$ height building of Stathopoulos et al. (2013) is taken as an example. As mentioned previously, the building in this current study is a steel structure with limited ductility concentrically braced frames as lateral force-resisting systems. Two other cases were considered for the comparison purposes, as the buildings were assumed to be moment resisting frame concrete structure and concrete building without a lateral force-resisting system. These buildings were designed for gravity and seismic loads, as well as, a structural analysis software was used to determine the fundamental frequencies of these buildings.

The three buildings have different damping ratio values, ranging from $2 \%$ to $5 \%$, and natural frequencies ranging from $0.5 \mathrm{~Hz}$ to $1.0 \mathrm{~Hz}$. Although they produce different gust factors $C_{g}$, similar torsional coefficients were found for the steel braced-frame building, the concrete building with moment resisting frame and the concrete building without lateral force-resisting system $(0.37,0.369$, and 0.35 , respectively). In addition, the corresponding shear coefficients computed in both directions were almost identical. Clearly, although building material and lateral force-resisting system directly affect the windinduced shear and torsion of a building, the differences that they create are not significant.

\section{Comparisons between ASCE/SEI 7-10 and experimental results from previous studies}

293 This section presents similar comparisons with those illustrated previously in Figs. 5 and 7. The same 294 buildings were considered using the ASCE/SEI 7-10 standard. Two different procedures, namely 295 Directional and Envelope, are available in ASCE/SEI 7-10 to determine the wind loads. The Directional 296 procedure can be applied to buildings of all heights, while the Envelope procedure is specified only for 297 low-rise buildings. The wind pressure, following the Directional and Envelope procedures, are as follows:

$$
p=q G C_{p}-q_{i}\left(G C_{p i}\right)(\text { Directional })
$$




$$
p=q_{h}\left[\left(G C_{p f}\right)-\left(G C_{p i}\right)\right](\text { Envelope })
$$

298 where $q$ is the velocity pressure evaluated at height $z$ above the ground for windward walls and at height $h$ 299 for leeward walls, $q_{h}$ and $q_{i}$ are the velocity pressure evaluated at mean roof height $h$, $G$ is the gust factor, $300 C_{p}$ is the external pressure coefficient, $\left(G C_{p i}\right)$ is the peak internal pressure coefficient, and $\left(G C_{p f}\right)$ is the 301 peak external pressure coefficient. Because it is assumed in the current paper that all buildings under 302 consideration are enclosed, the internal pressure effects have been neglected, since they cancel each other 303 on opposite walls.

The ASCE/SEI 7-10 specifies four partial loading cases for the Directional procedure, and four cases for the Envelope procedure (including two torsional load cases), as shown in Figs. 8 and 9, respectively. Clearly, Cases 1 and 3 of the Directional Procedure are similar to NBCC 2015, but a difference can easily be witnessed in the torsional load cases (Cases 2 and 4). In these cases, the same approach as Cases B and D (see Fig. 9) is used, except that a torsion $M_{T}$ is defined explicitly and the wind pressure is distributed uniformly over the full tributary area of the building wall face. In terms of low-rise buildings, two additional torsional load cases are added to the Envelope procedure besides two conventional load cases as similar to NBCC 2015. In these additional cases, only $25 \%$ of the full wind 312 pressures are applied to half of the building wall, while the rest remain unchanged as the conventional 313 case, which in turn creates a greater amount of torsion comparing to the Canadian provisions.

For low-rise buildings, maximum base shears and torsions are obtained by considering both 315 Directional and Envelope procedures. While the maximum base shears are determined by Case 1 of the 316 Directional procedure, the torsional effect is found to be maximum in Case B (torsion) of the Envelope 317 procedure. For medium-rise buildings, only the Directional procedure is carried out, where Case 1 creates 318 the maximum shear forces. At the same time, the most severe torsional case is determined by either Case 3192 or Case 4. After the maximum base shears and torsions have been obtained for all buildings, shear and torsional coefficients are computed following Eqs. (8) and (9). 
All the ASCE/SEI 7-10 values are multiplied by $1.53^{2}$ due to the difference between the 3 -second and 1-hour wind speed used in NBCC 2015 and ASCE 7-10, respectively. Particularly, the wind speed in

323 NBCC 2015, measured over a period of 1 hour, is 1.53 times smaller than that of the ASCE/SEI 7-10, 324 which is calculated over a period of 3 seconds (Durst 1960).

Figure 10 shows similar torsional coefficient values computed from experimental tests reported in past studies and those computed according to ASCE/SEI 7-10 provisions. For low-rise buildings, the

327 American standard has generated almost the same results as the experimental values on three out of four 328 studies. The study of Tamura et al. (2003) in urban terrain is the only one that gives a notable 329 discrepancy.

Better agreements have been illustrated in the results for medium-rise buildings. The highest difference is from the study of Stathopoulos et al. (2013), where an experimental coefficient is found equal to $75 \%$ of that from the American provision. Other findings are very similar: experimental results are roughly $95 \%$ of code computations.

Figure 11 compares shear coefficients for low-rise and medium-rise buildings obtained using the ASCE/SEI 7-10 provisions and the respective wind tunnel results. Generally, the discrepancies induced in 336 low-rise buildings are slightly higher than those in medium-rise buildings. All points shown in the graph 337 of medium-rise buildings almost overlap with the $45^{\circ}$ line. Stathopoulos et al. (2013) have again given 338 identical values to those provided by the American standard. This resemblance tendency has been 339 previously identified in the case of NBCC 2015 and plotted in Fig. 7. In terms of low-rise buildings, 340 overestimated results were found in the comparisons with Tamura et al. (2003) building in open terrain.

341 This is possible due to the differences in the definition of open terrain used in both cases.

342 Overall, the ASCE/SEI 7-10 provisions have given analogous shear results comparing to the wind 343 tunnel results. 
In this section, the NBCC 2015 and ASCE/SEI 7-10 wind provisions are applied to five buildings, with the same horizontal dimensions but different heights ranging from $14.8 \mathrm{~m}$ (low-rise building) to $43.6 \mathrm{~m}$ (medium-rise building). The building heights ascend in a step of $7.2 \mathrm{~m}$. The typical plan and elevation views of the five buildings are presented in Fig. 12, where B and L are the shorter and longer horizontal dimensions. Based on these buildings' configurations and natural frequencies, the wind static procedure is applied for low-rise buildings and the dynamic procedure is applied for medium-rise buildings (see Table 2). All partial loading cases are carried out to seek the highest wind-induced shears and torsions provided by both codes. The results are shown in Fig. 13.

According to NBCC 2015 provisions, the static procedure is applied for the low-rise building $(14.8 \mathrm{~m})$, while the medium-rise buildings are computed with the dynamic procedure. Similar to the previous sections, Cases B and D are carried out with the wind tributary area determined following Eq. (6). Very small torsional coefficient is produced from the low-rise building. Thus, the torsional coefficient rises immensely when building class changes from low-rise to medium-rise building (14.8 $\mathrm{m}$ to $22.0 \mathrm{~m}$ ) and can be witnessed easily from the sudden change in the $C_{T}$ line's alignment in Fig. 13. Moreover, this jump seems to be noticeably high comparing to the average of 1.3 resulted for the same height steps which are: $22.0 \mathrm{~m}$ to $29.2 \mathrm{~m}, 29.2 \mathrm{~m}$ to $36.4 \mathrm{~m}$ and $36.4 \mathrm{~m}$ to $43.6 \mathrm{~m}$. In terms of shear coefficients, the differences are apparently less remarkable. In the N-S direction, the difference between the low-rise and medium-rise buildings is just slightly greater than that between two medium-rise buildings with consecutive heights and decreases largely when it comes to the W-E direction.

Through the good agreement with experimental values (Fig. 10), the ASCE/SEI 7-10 wind provisions are believed to have successfully predicted the wind effects and can be considered a good reference to evaluate the adequacy of other codes. Therefore, the coefficients found in NBCC 2015 are compared with the values provided by the ASCE/SEI 7-10 provisions on the same set of buildings. Significant discrepancies are found regarding torsional coefficients, especially in the case of low-rise buildings. Firstly, the torsional coefficient provided in NBCC 2015 for low-rise buildings is much smaller than that of ASCE/SEI 7-10, implying a serious underestimation of NBCC 2015 in evaluating the wind- 
371 induced torsional effects on low-rise buildings. Secondly, for medium-rise buildings, NBCC 2015 has

372 provided torsional coefficients roughly 1.5 times higher than those of ASCE/SEI 7-10. Additionally, this

373 trend increases with the building height and is greater than the $6 \%$ difference shown in Figs. 5 and 10

374 where the same computations were made for smaller buildings. Indeed, the longer horizontal dimension

375 of the buildings in this section $(150.5 \mathrm{~m})$ is more than double the maximum dimension from the previous

376 comparisons $(61.0 \mathrm{~m})$. Therefore, it can be concluded that the recommended tributary area is conservative

377 for determining the torsional effects of large and high buildings.

378 Conversely, in terms of shear coefficients, Fig.13 shows that both codes have given similar results

379 regardless of building height. Thus, although the discrepancies fluctuate with the ascending building

380 heights, the two codes only give differences within 10\%. Excluding the results of low-rise buildings, all

381 shear coefficients resulted from the NBCC 2015 are higher than those from the ASCE/SEI 7-10. It is also

382 noticeable that the gap between the shear coefficients computed for the low-rise building (14.8 $\mathrm{m}$ height)

383 and those for the $22.0 \mathrm{~m}$ high building (medium-rise) is significantly higher comparing to the difference

384 between the other medium-rise buildings. For example, the shear coefficients of the $14.8 \mathrm{~m}$ high building

385 in both orthogonal directions are on average about $50 \%$ of those of the $22.0 \mathrm{~m}$ high building. The average

386 between the other medium-rise buildings is almost $80 \%$. However, this difference does not imply any

387 underestimation in shear computations in low-rise buildings as similar trend between code provisions and

388 wind tunnel test results has been found in previous sections.

\section{Recommendations}

390 Some recommendations are made here to improve the adequacy of the NBCC 2015 provisions in terms of 391 torsional effects.

For low-rise buildings, according to Fig. 6, the application of wind partial loading cases into low393 rise buildings has significantly improved the torsion assessments of NBCC 2015, although some 394 discrepancies still occur. However, by adding two torsional load cases and distributing the wind pressure 395 on building faces differently from NBCC 2015, the American standard provisions have yielded closer 
coefficients to results from wind tunnel tests (Figs. 10 and 11). Therefore, it is recommended that the torsion methodology provided by ASCE/SEI 7-10 for low-rise buildings to be applied to the NBCC 2015 .

For medium-rise buildings, by applying the wind pressure on half of the wall area (Eq. 6), Case B and Case D have resulted in adequate torsions (Fig. 5). However, when the building horizontal dimensions and height increase, this method can provide conservative results with an increasing trend, as can be seen in Fig. 13. Meanwhile, the ASCE/SEI 7-10 standard can provide more appropriate results regardless of building configurations, as is indicated through the comparisons with experimental coefficients in Fig. 10. Consequently, the adequacy of torsional results in medium-rise buildings can be improved in the NBCC 2015 provisions by explicitly defining an additional moment and eccentricity in each torsional loading case as in the ASCE/SEI 7-10.

\section{Summary and Conclusion}

Results from previous wind tunnel tests have shown that the NBCC 2015 provides adequate assessment of wind effects on low-rise and medium-rise buildings with the only exception of torsional effects on lowrise buildings, which are underestimated significantly. Load cases B and D, available for medium-rise buildings, have been applied, and yielded improved results, although still low compared to the experimental results.

Through the comparisons with ASCE/SEI 7-10, good agreement in shear computations has been found between the two sets of provisions. For medium-rise buildings, if the wind loads are placed on half of the building wall in Case B and Case D, appropriate results can be obtained from the NBCC 2015 although conservative torsions may arise when the building horizontal dimensions and height raise. The comparisons also show that the torsional effects evaluated by NBCC 2015 for low-rise buildings are seriously underestimated.

In conclusion, it is suggested that the ASCE/SEI 7-10 torsion methodology to be applied in future editions of NBCC for both low-rise and medium-rise buildings in order to attain appropriate torsional evaluations. 


\section{Acknowledgments}

422 The authors would like to acknowledge the financial support of the Québec Fonds pour la Recherche sur 423 la Nature et les Technologies (FQRNT) for the Centre d'Études Interuniversitaires des Structures sous 424 Charges Extrêmes (CEISCE).

425

426

427

428

429

430

431

432

433

434

435

\section{References}

ASCE/SEI 7-10. 2010. Minimum design loads for buildings and other structures. Structural Engineering Institute of ASCE, Reston, VA.

AS-NZS 1170-2. 2011. Structural design actions - Part 2: Wind actions (By Authority of New Zealand Structure Verification Method B1/VM1).

Computer and Structure, Inc., USA. 2016. CSI Analysis Reference Manual for ETABS.

Durst, C.S. 1960. Wind speeds over short periods of time. Meteor. Mag. 89, 181-187.

EN 1991-1-1. 2005. Eurocode 1: Actions on structures - Part 1-4: General actions - Wind actions.

Isyumov, N. and Case, P.C. 2000. Wind-induced torsional loads and responses of buildings, Proceedings of Structures Congress, Philadelphia, Pennsylvania, USA, Sponsored by ASCE/SEI, May 8-10.

Keast, D.C., Barbagallo, A., Wood, G.S. 2012. Correlation of wind load combinations including torsion on medium-rise buildings. Wind and Structures, An International Journal, 15(5), 423-439.

National Research Councile of Canada. 2015. National Building Code of Canada - Part 4. Ottawa, On.

Stathopoulos, T., Elsharawy, M., Galal, K. 2013. Wind load combinations including torsion for rectangular medium-rise buildings. Int. J. of high-rise buildings. Sept. 2013, Vol. 2, no. 3, 245-255.

Tamura, Y., Kikuchi, H., Hibi, K. 2003. Quasi-static wind load combinations for low- and middle-rise buildings. Journal of Wind Engineering and Industrial Aerodynamics, 91, 1613-1625. 
452 List of figure captions

453 Fig. 1: Load cases for medium-rise buildings after NBCC 2015.

454 Fig. 2: Load cases for low-rise buildings after NBCC 2015.

$455 \quad$ Fig. 3: Load Case D for medium-rise buildings analyzed in $x$ and $y$ directions.

456 Fig. 4: Load cases for low-rise flat roof buildings according to NBCC 2015 provisions.

457 Fig. 5: Comparison of torsional coefficients for low-rise and medium-rise buildings in NBCC 2015 with 458 experimental results from previous studies.

459 Fig. 6: Comparison of torsional coefficients for low-rise in NBCC 2015 (following partial loading cases, 460 PL) with experimental results from previous studies.

461 Fig. 7: Comparison of shear coefficients for low-rise and medium-rise buildings in NBCC 2015 with 462 experimental results from previous studies.

463 Fig. 8: Partial loading case for the Directional procedure after ASCE/SEI 7-10.

464 Fig. 9: Partial loading cases for the Envelope procedure after ASCE/SEI 7-10.

465 Fig. 10: Comparison of torsional coefficients for low-rise and medium-rise buildings in ASCE/SEI 7-10 466 with experimental results from previous studies.

467 Fig. 11: Comparison of shear coefficients for low-rise and medium-rise buildings in ASCE/SEI 7-10 with 468 experimental results from previous studies.

$469 \quad$ Fig. 12: Common plan and elevation views of the buildings in the current study. 
470 Fig. 13: Shear and torsional coefficients according to NBCC 2015 and ASCE/SEI 7-10.

471

472

473

$474 \quad$ List of table caption

475 Table 1: Building dimensions and exposure condition.

476 Table 2: Computation procedure for the buildings in the previous and current studies according

477 to NBCC.

478 Table 3: Original and transformed definition of shear and torsional coefficients in previous

479 studies. 
Tables

Table 1: Building dimensions and exposure conditions.

\begin{tabular}{|c|c|c|c|c|c|}
\hline \multicolumn{2}{|c|}{ Study name } & $\begin{array}{c}\text { Isyumov and } \\
\text { Case (2000) }\end{array}$ & $\begin{array}{c}\text { Tamura et al. } \\
\text { (2003) }\end{array}$ & Keast et al. (2012) & $\begin{array}{c}\text { Stathopoulos et al. } \\
\text { (2013) }\end{array}$ \\
\hline \multicolumn{2}{|c|}{$\begin{array}{l}\text { Type of building } \\
\text { exposure in } \\
\text { experiments }\end{array}$} & Urban & Urban/Open & Open & Open \\
\hline \multirow{3}{*}{$\begin{array}{l}\text { Low-rise } \\
\text { buildings }\end{array}$} & $\mathrm{B}(\mathrm{m})$ & 9.75 & 30 & & 39 \\
\hline & $\mathrm{L}(\mathrm{m})$ & 29.26 & 42.5 & & 61 \\
\hline & $\mathrm{H}(\mathrm{m})$ & 4.88 & 12.5 & & 20 \\
\hline \multirow{6}{*}{$\begin{array}{l}\text { Medium- } \\
\text { rise } \\
\text { buildings }\end{array}$} & $\mathrm{B}(\mathrm{m})$ & & & & 39 \\
\hline & $\mathrm{L}(\mathrm{m})$ & & & & 61 \\
\hline & $\mathrm{H}(\mathrm{m})$ & & & & 30 \\
\hline & $\mathrm{B}(\mathrm{m})$ & & 25 & 20 & 39 \\
\hline & $\mathrm{L}(\mathrm{m})$ & & 50 & 40 & 61 \\
\hline & $\mathrm{H}(\mathrm{m})$ & & 50 & 60 & 40 \\
\hline
\end{tabular}

Table 2: Computation procedure for the buildings in the previous and current studies according to NBCC.

\begin{tabular}{lcccc}
\hline Study & $\mathrm{f}_{\mathrm{n}}$ & $\mathrm{H} / \mathrm{w}$ & $\mathrm{H}(\mathrm{m})$ & \multicolumn{2}{c}{ Procedure } \\
\hline \multicolumn{1}{c}{ Computation procedure for the buildings in the previous studies according to NBCC } \\
\hline Isyumov and Case (2000) & 4.10 & 0.50 & 4.88 & Static \\
\hline \multirow{2}{*}{ Tamura et al. (2003) } & 1.60 & 0.42 & 12.5 & Static \\
\cline { 2 - 5 } & 0.40 & 2.00 & 50 & Dynamic \\
\hline Keast et al. (2012) & 0.33 & 3.00 & 60 & Dynamic \\
\hline \multirow{3}{*}{ Stathopoulos et al. (2013) } & 1.00 & 0.51 & 20 & Dynamic \\
\cline { 2 - 4 } & 0.67 & 0.77 & 30 & Dynamic \\
\cline { 2 - 4 } & 0.50 & 1.03 & 40 & Dynamic \\
\hline \multicolumn{1}{c}{ Computation procedure for the buildings in the current study according to NBCC 2015 } \\
\cline { 2 - 4 } Current study & 1.19 & 0.39 & 14.8 & Static \\
\cline { 2 - 4 } & 0.79 & 0.58 & 22 & Dynamic \\
\cline { 2 - 4 } & 0.54 & 0.77 & 29.2 & Dynamic \\
\cline { 2 - 4 } & 0.46 & 0.96 & 36.4 & Dynamic \\
\cline { 2 - 4 } & 0.37 & 1.15 & 43.6 & Dynamic \\
\hline
\end{tabular}


Table 3: Original and transformed definition of shear and torsional coefficients in previous studies.

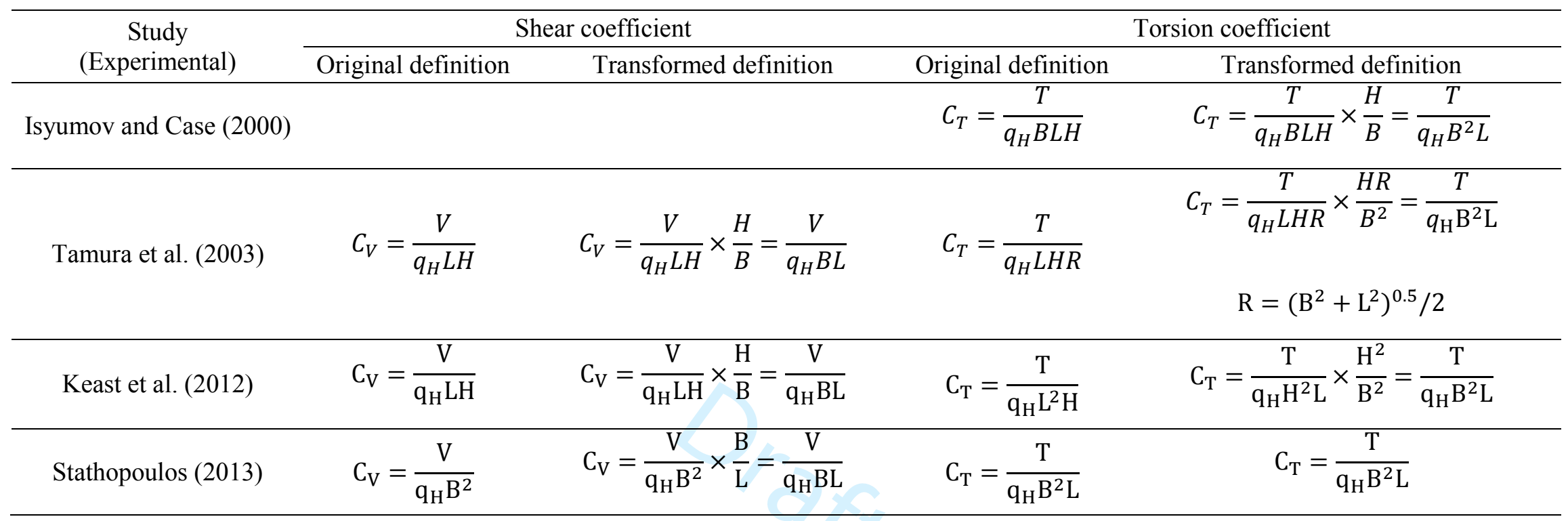




\section{Figures}

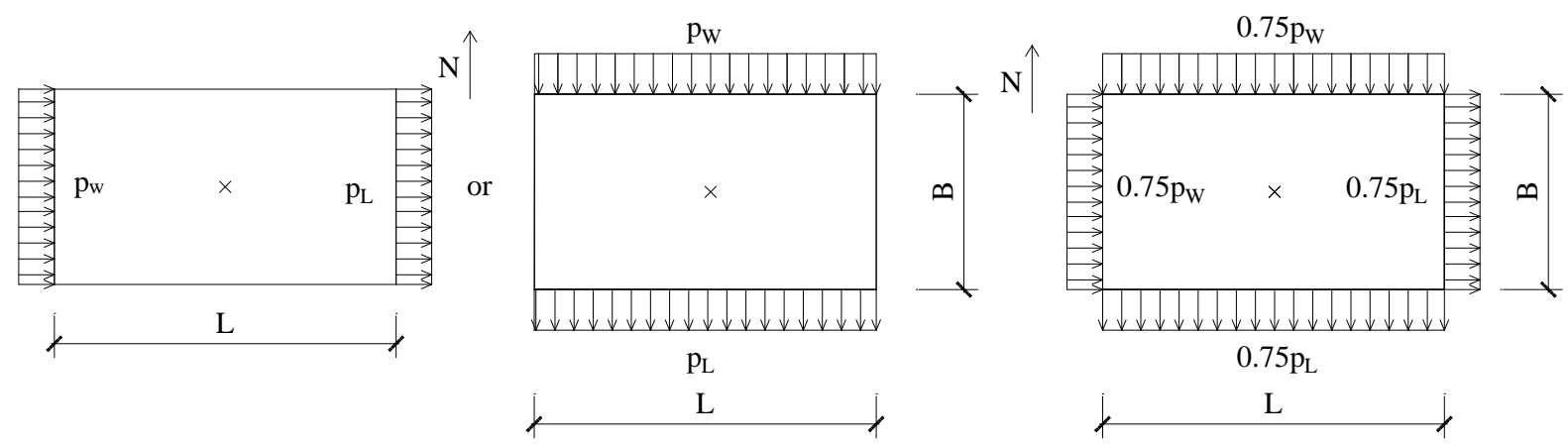

Case A: Full wind pressure applied in both diretions separately

Case C: $75 \%$ of full wind pressure applied in both diretions simultaneously

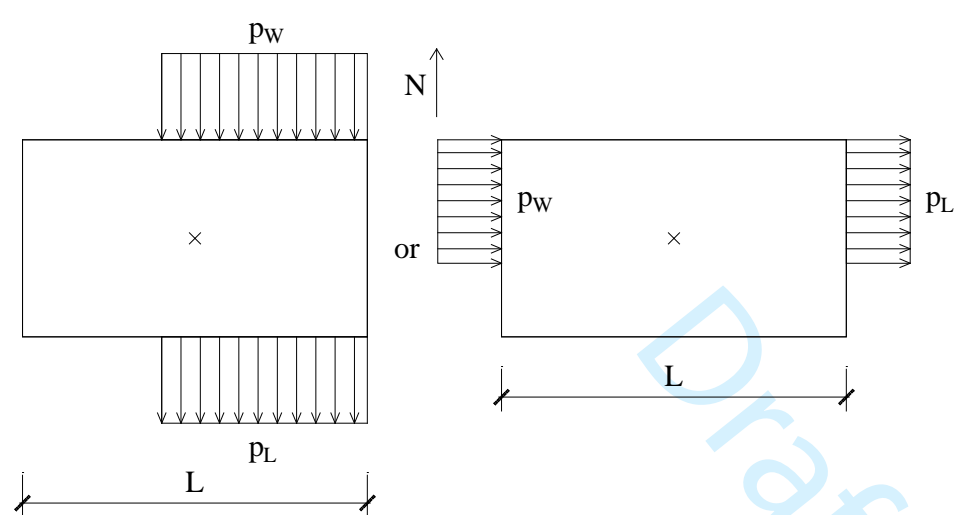

Case B: Case A wind pressure applied only on parts of wall faces

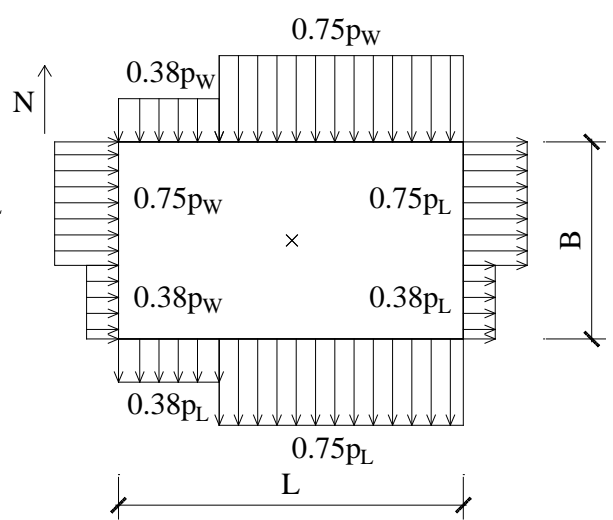

Case D: $50 \%$ of case $\mathrm{C}$ wind load removed from part of projected area

Fig. 1: Load cases for medium-rise buildings after NBCC 2015. 

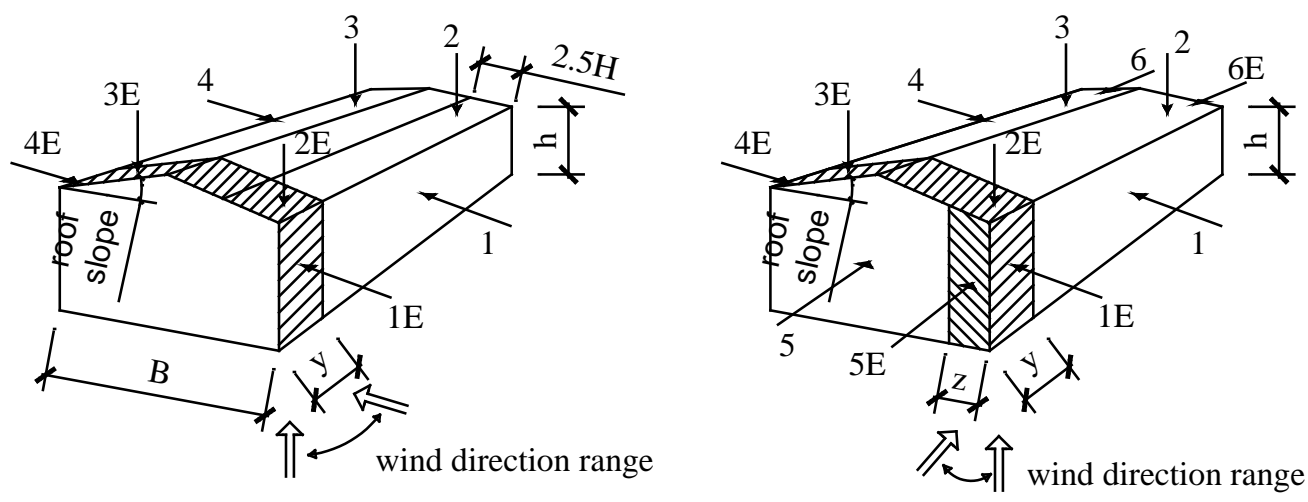

Load case A: winds generally perpendicular to ridge

Load case B: winds generally parallel to ridge

\begin{tabular}{|l|c|c|c|c|c|c|c|c|}
\hline \multirow{2}{*}{ Roof slope } & \multicolumn{7}{|c|}{ Building surfaces - Case A } \\
\cline { 2 - 9 } & 1 & $1 \mathrm{E}$ & 2 & $2 \mathrm{E}$ & 3 & $3 \mathrm{E}$ & 4 & $4 \mathrm{E}$ \\
\hline $0^{\circ}$ to $5^{\circ}$ & 0.75 & 1.15 & -1.3 & -2.0 & -0.7 & -1.0 & -0.55 & -0.8 \\
\hline
\end{tabular}

\begin{tabular}{|l|c|c|c|c|c|c|c|c|c|c|c|c|}
\hline \multirow{2}{*}{ Roof slope } & \multicolumn{10}{|c|}{ Building surfaces - Case B } \\
\cline { 2 - 12 } & 1 & $1 \mathrm{E}$ & 2 & $2 \mathrm{E}$ & 3 & $3 \mathrm{E}$ & 4 & $4 \mathrm{E}$ & 5 & $5 \mathrm{E}$ & 6 & $6 \mathrm{E}$ \\
\hline $0^{\circ}$ to $90^{\circ}$ & -0.85 & -0.9 & -1.3 & -2.0 & -0.7 & -1.0 & -0.85 & -0.9 & 0.75 & 1.15 & -0.55 & -0.8 \\
\hline
\end{tabular}

End-zone width y should be the greater of $6 \mathrm{~m}$ or $2 \mathrm{z}$, where $\mathrm{z}$ is the gable wall end-zone defined for Load Case $\mathrm{B}$ below. Alternatively, for buildings with frames; the end-zone y may be the distance between the end and the first interior frame.

End-zone width $\mathrm{z}$ is the lesser of $10 \%$ of the least horizontal dimension or $40 \%$ of height, $\mathrm{H}$, but not less than $4 \%$ of the least horizontal dimension or $1 \mathrm{~m}$.

Fig. 2: Load cases for low-rise buildings after NBCC 2015. 


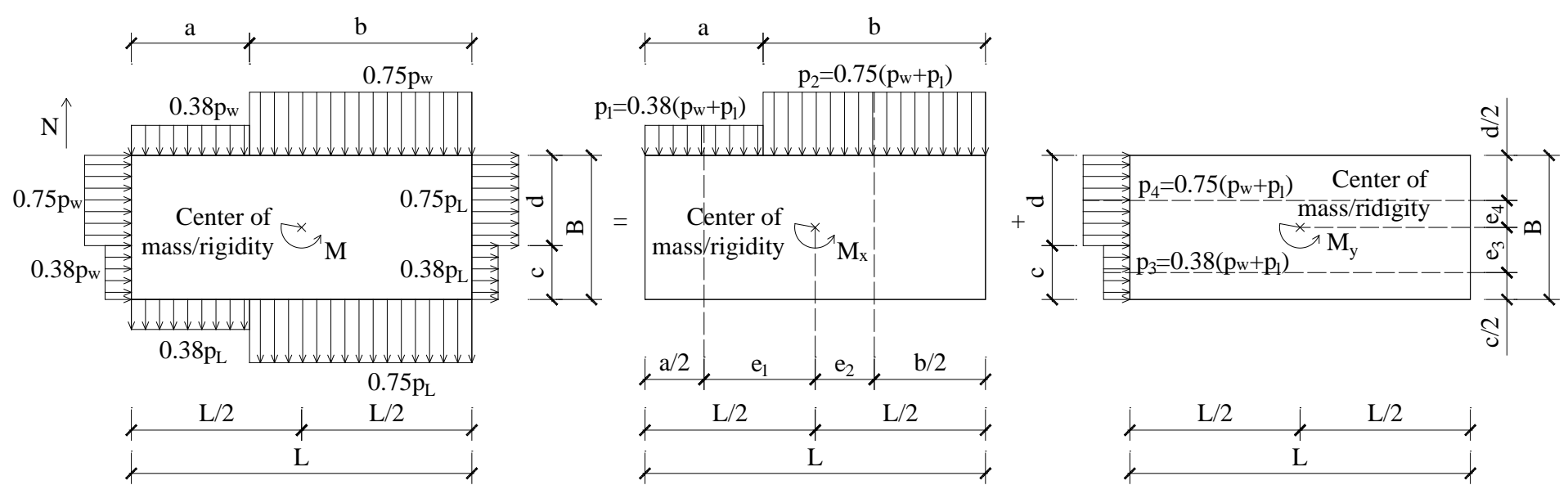

Fig. 3: Load Case D for medium-rise buildings analyzed in $x$ and $y$ directions. 

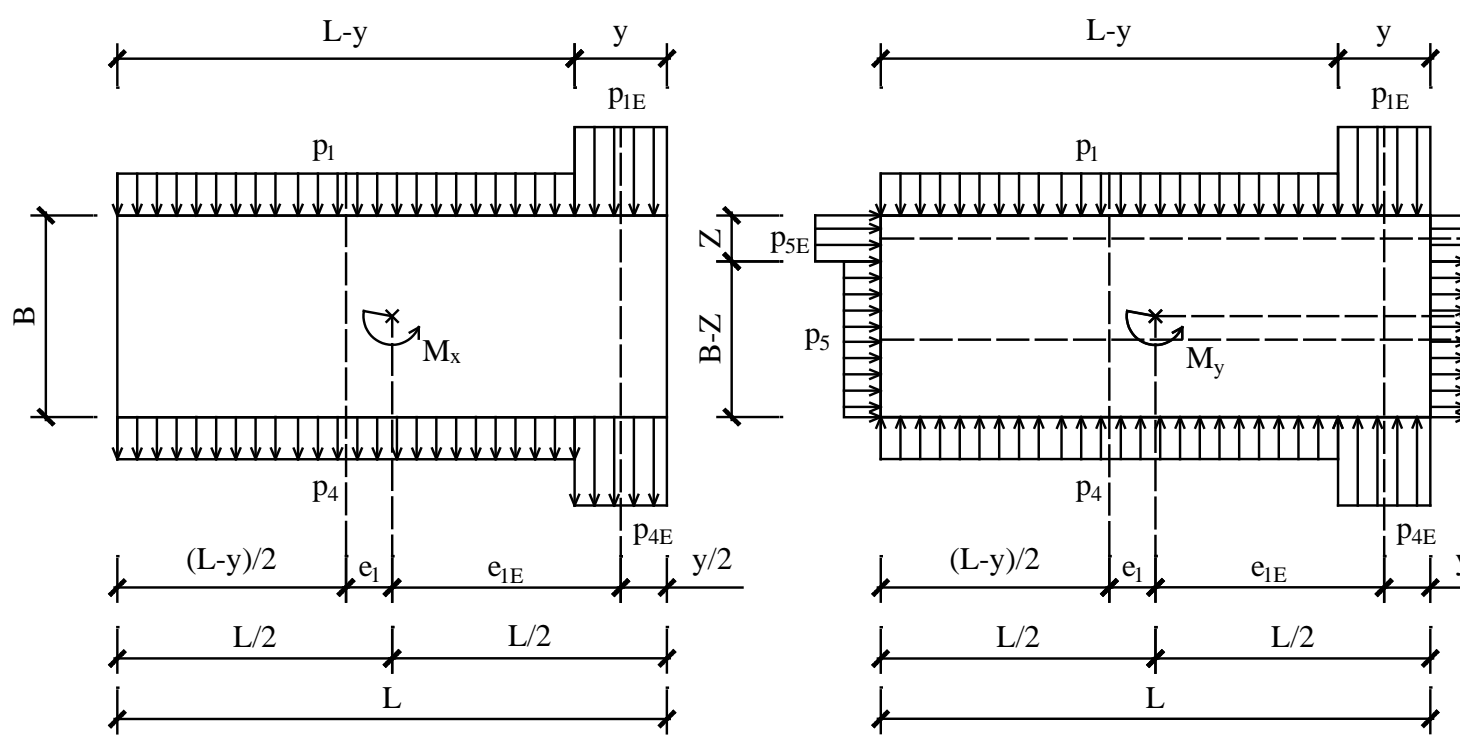

Load case A: winds generally perpendicular to ridge

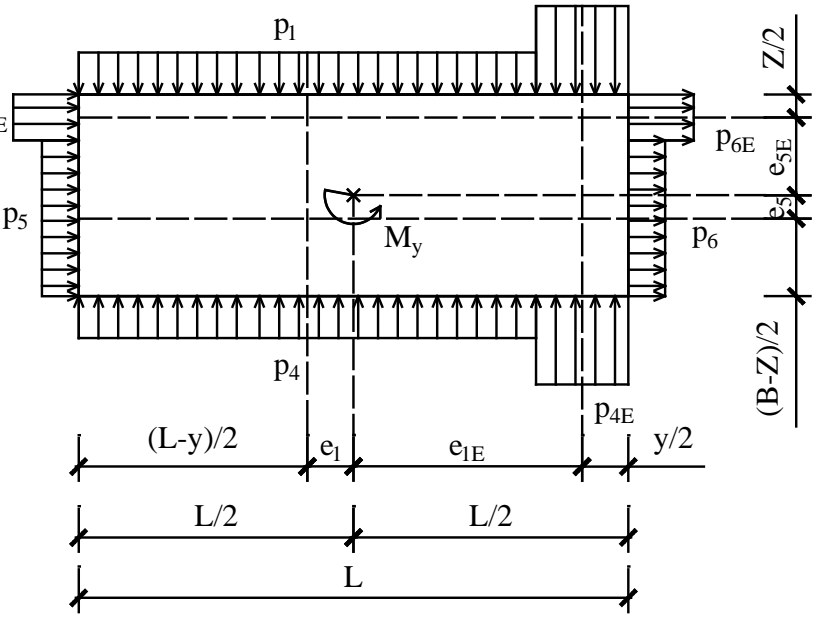

End-zone width y should be the greater of $6 \mathrm{~m}$ or $2 \mathrm{z}$, where $\mathrm{z}$ is the gable wall end-zone defined for Load Case $\mathrm{B}$ below. Alternatively, for buildings with frames; the end-zone y may be the distance between the end and the first interior frame.

End-zone width $\mathrm{z}$ is the lesser of $10 \%$ of the least horizontal dimension or $40 \%$ of height, $\mathrm{H}$, but not less than $4 \%$ of the least horizontal dimension or $1 \mathrm{~m}$.

Fig. 4: Load cases for low-rise flat roof buildings according to NBCC 2015 provisions. 


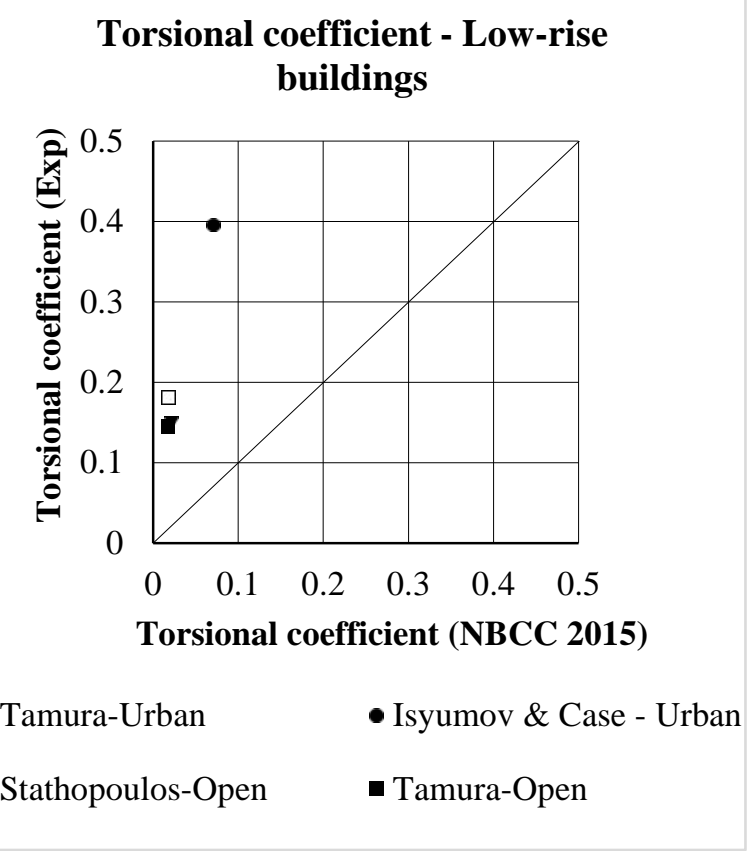

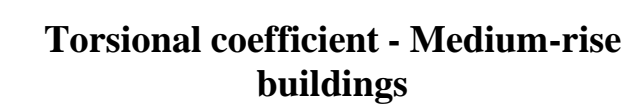

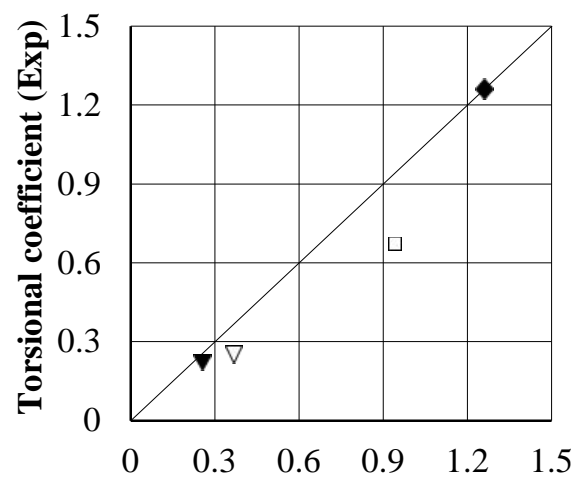

Torsional coefficient (NBCC 2015)

$\square$ Tamura-Urban $\quad \nabla$ Stathopoulos-Open-30m

$\nabla$ Stathopoulos-Open-40m $\bullet$ Keast-Open

Fig. 5: Comparison of torsional coefficients for low-rise and medium-rise buildings in NBCC 2015 with experimental results from previous studies. 


\section{Torsional coefficient - Low-rise buildings (following partial loading cases for medium-rise buildings)}

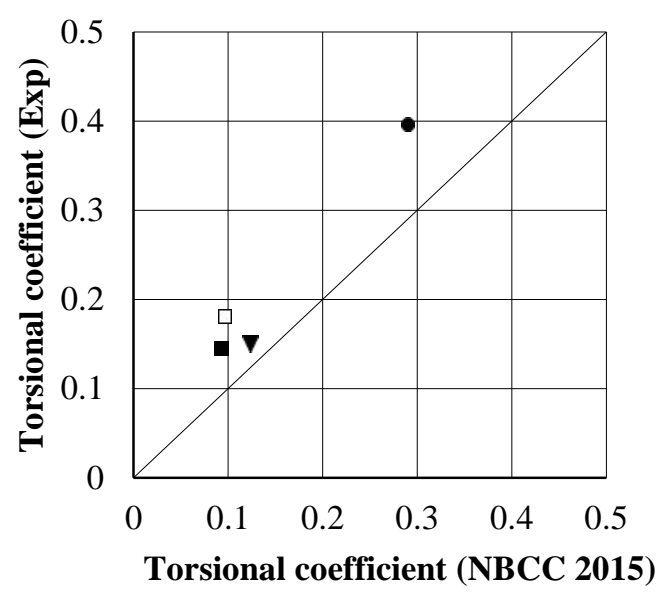

$\square$ Tamura-Urban-PL

- Isyumov \& Case - Urban-PL

v Stathopoulos-Open-PL

- Tamura-Open-PL

Fig. 6: Comparison of torsional coefficients for low-rise buildings in NBCC 2015 (following partial loading cases for medium-rise building, PL) with experimental results from previous studies. 


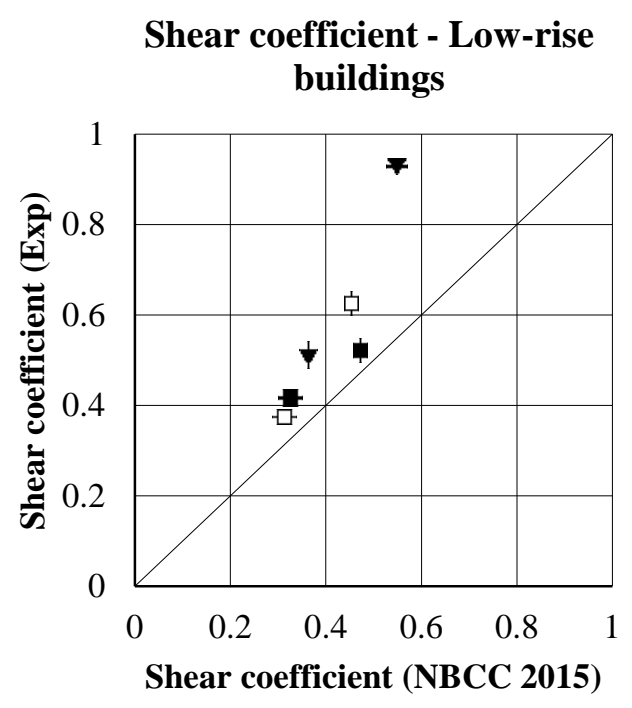

- Tamura-Urban-W-E

† Stathopoulos-Open-W-E

ㅁ Tamura-Open-W-E

- Tamura-Urban-N-S

₹ Stathopoulos-Open-N-S

ф Tamura-Open-N-S

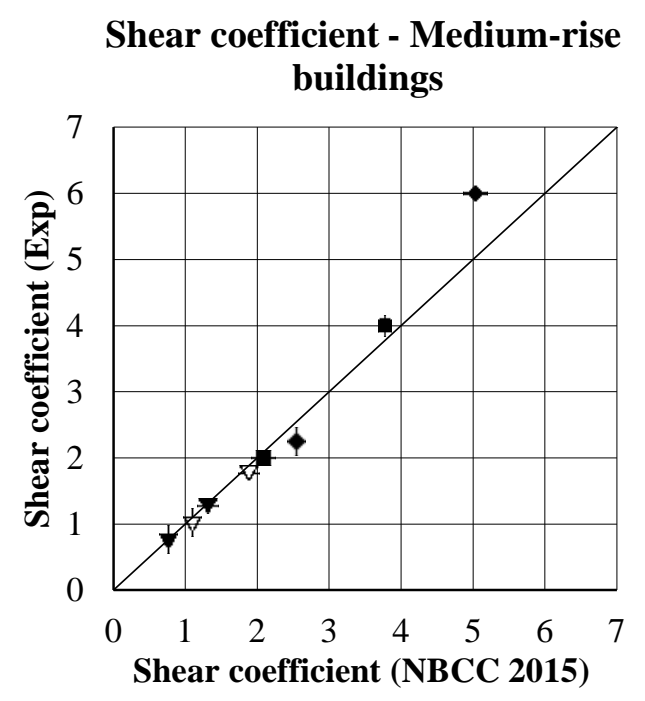

- Tamura-Urban-W-E

\ Stathopoulos-Open-W-E-30m

+ Keast-Open-W-E

₹Stathopoulos-Open-N-S-30m
- Tamura-Urban-N-S

i Stathopoulos-Open-W-E-40m

- Keast-Open-N-S

$\gtrless$ Stathopoulos-Open-N-S-40m

Fig. 7: Comparison of shear coefficients for low-rise and medium-rise buildings in NBCC 2015 with experimental results from previous studies. 

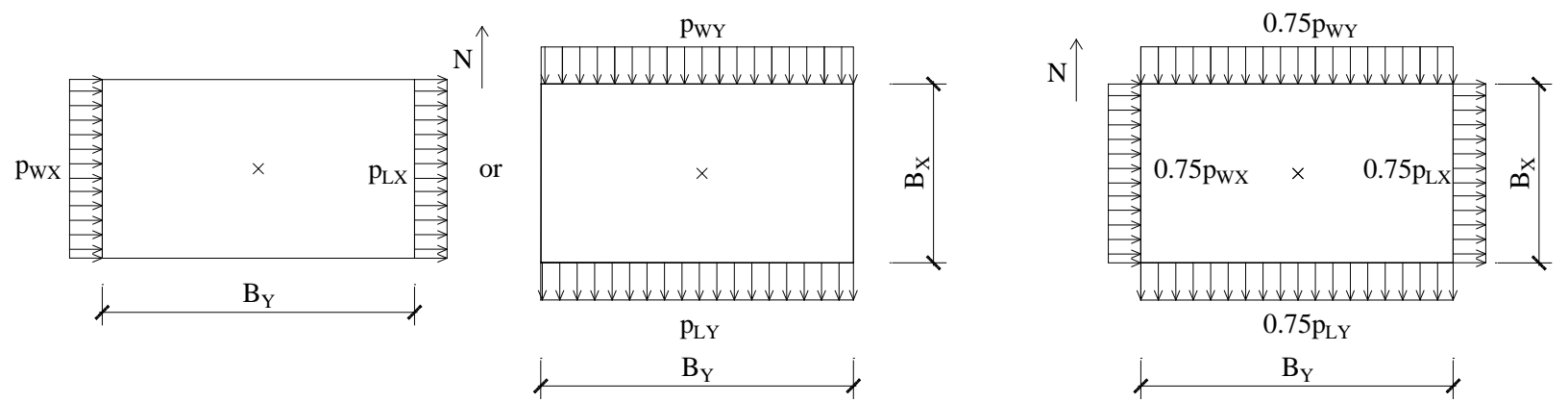

Case 1: Full design wind pressure acting on the projected area perpendicular to each principal axis of the structure, considered separately along each principal axis.
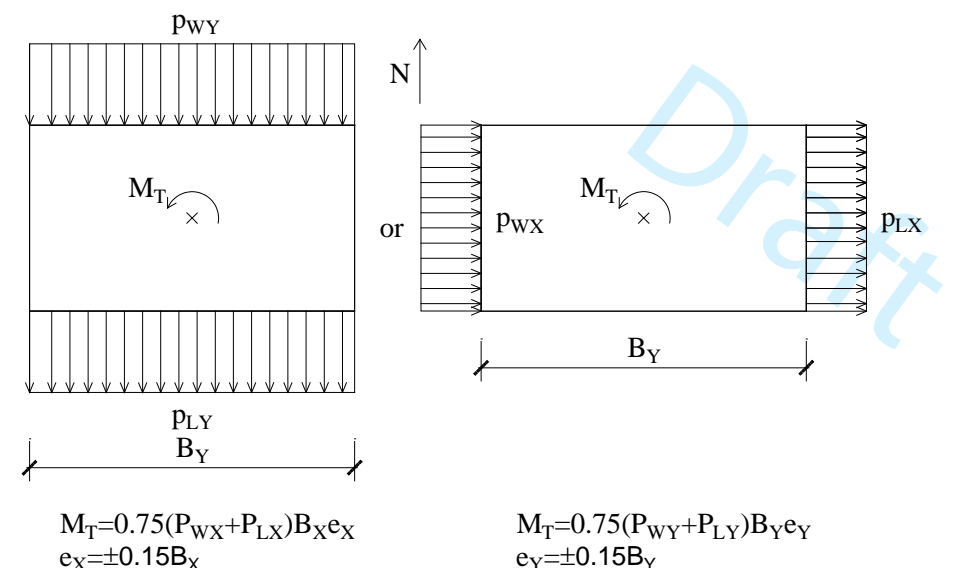

Case 3: Wind loading as defined in Case 1, but considered to act simultaneously at $75 \%$ of the specified value.

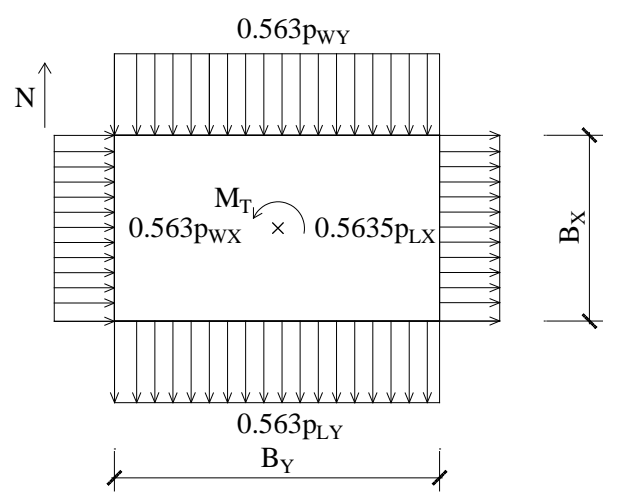

$\begin{array}{ll}M_{T}=0.563\left(P_{W X}+P_{L X}\right) B_{X} e_{X}+0.563\left(P_{W Y}+P_{L Y}\right) B_{Y} e_{Y} \\ e_{X}= \pm 0.15 B_{X} & e_{Y}= \pm 0.15 B_{Y}\end{array}$

$$
\begin{aligned}
& \mathrm{M}_{\mathrm{T}}=0.75\left(\mathrm{P}_{\mathrm{WY}}+\mathrm{P}_{\mathrm{LY}}\right) \mathrm{B}_{\mathrm{Y}} \mathrm{e}_{\mathrm{Y}} \\
& \mathrm{e}_{\mathrm{Y}}= \pm 0.15 \mathrm{~B}_{\mathrm{Y}}
\end{aligned}
$$

$\mathrm{e}_{\mathrm{Y}}= \pm 0.15 \mathrm{~B}_{\mathrm{Y}}$

Case 2: Three quarters of the design wind pressure acting on the projected area perpendicular to each principal axis of the structure in conjunction with a torsional moment as shown, considered separately for each principal axis.

Case 4: Wind loading as defined in Case 2, but considered to act simultaneously at $75 \%$ of the specified value.

Partial loading

case

for

the

Directional

procedure

after

ASCE/SEI 

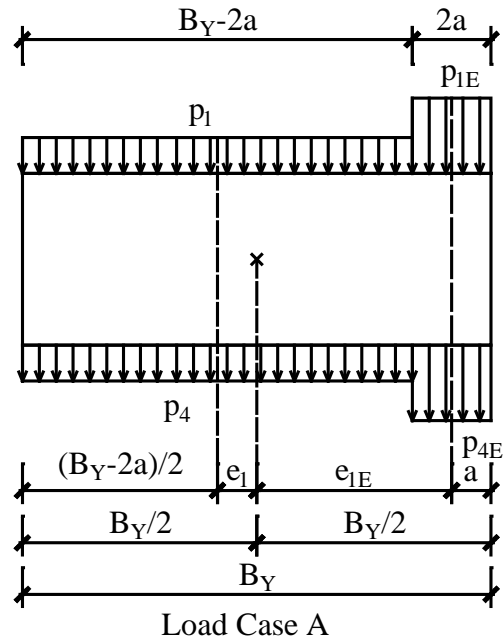

Load Case A
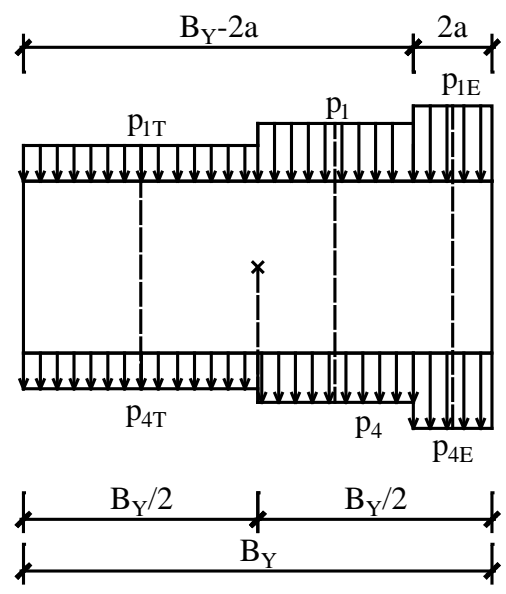

Case A Torsion

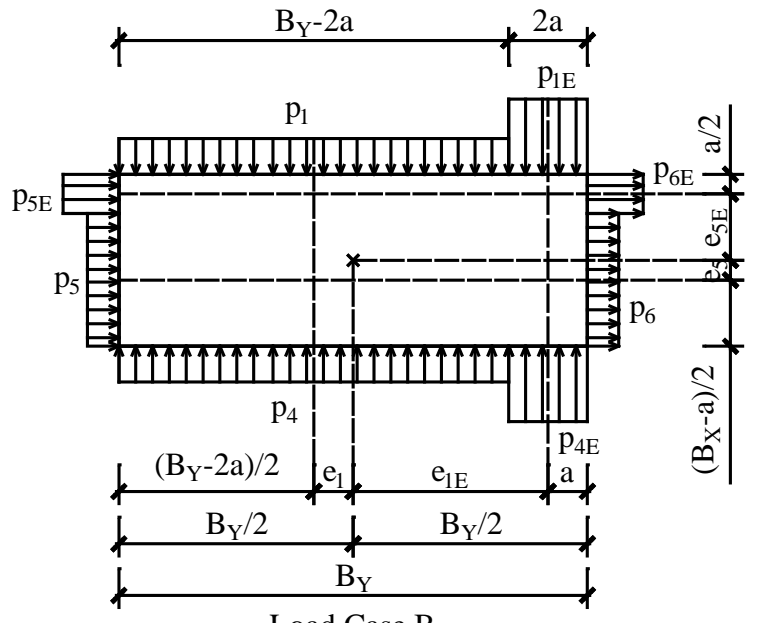

Load Case B
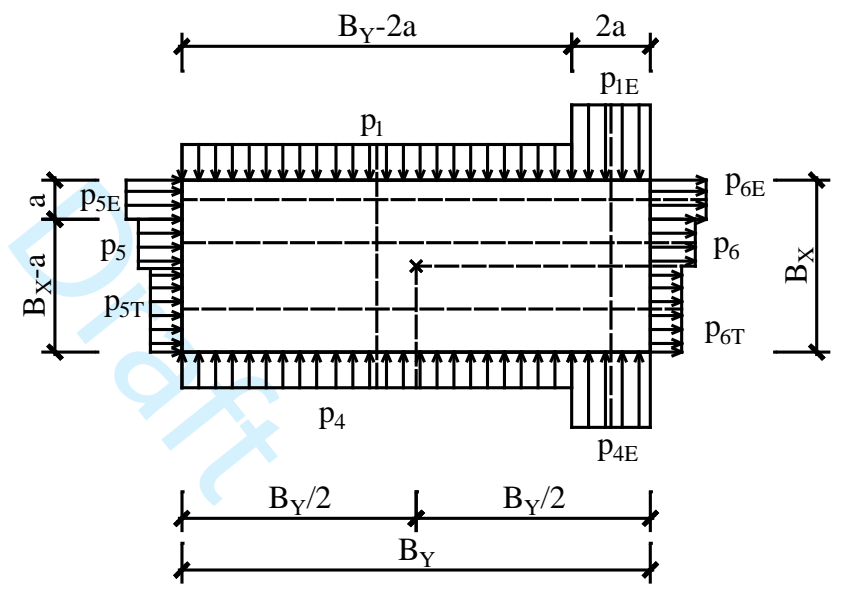

Case B Torsion

a: $10 \%$ of least horizontal dimension or $0.4 \mathrm{~h}$, whichever is smaller, but not less than either $4 \%$ of least horizontal dimension or $3 \mathrm{ft}(0.9 \mathrm{~m})$

Fig. 9: Partial loading cases for the Envelope procedure after ASCE/SEI 7-10. 

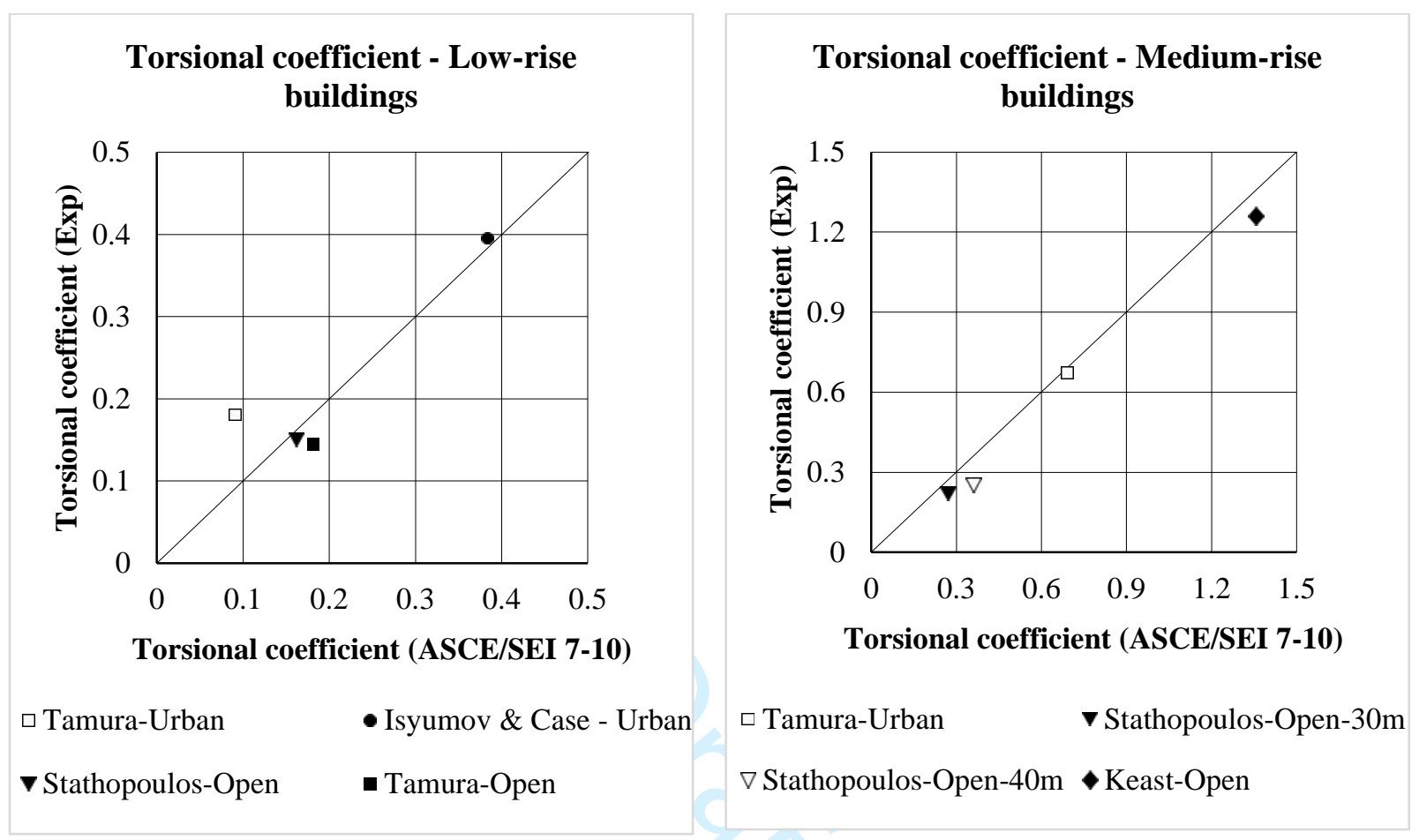

Fig. 10: Comparison of torsional coefficients for low-rise and medium-rise buildings in ASCE/SEI 7-10 with experimental results from previous studies. 


\section{Shear coefficient - Low-rise} buildings

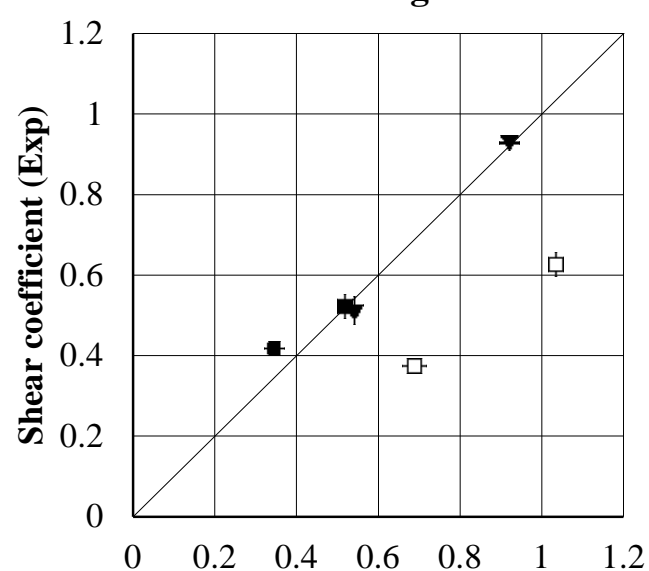

Shear coefficient (ASCE/SEI 7-10)

- Tamura-Urban-W-E

+ Stathopoulos-Open-W-E

- Tamura-Urban-N-S

$\square$ Tamura-Open-W-E

ф Tamura-Open-N-S

\section{Shear coefficient - Medium-rise} buildings

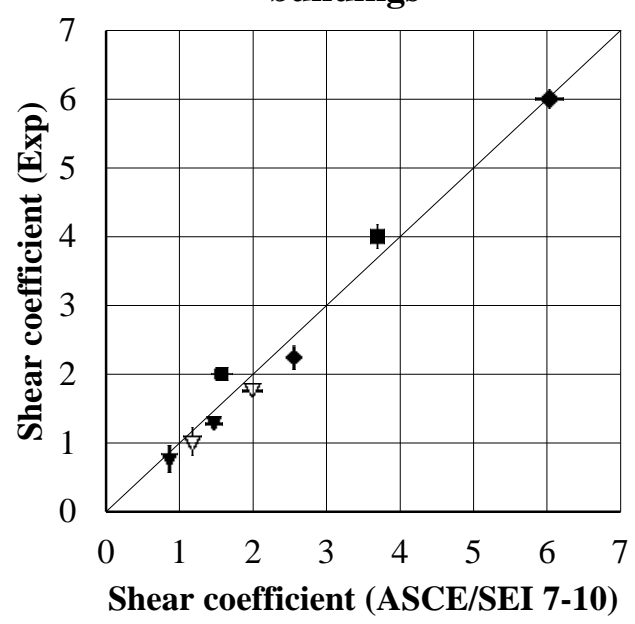

- Tamura-Urban-W-E

† Stathopoulos-Open-W-E-30m

- Keast-Open-W-E

* Stathopoulos-Open-N-S-30m
- Tamura-Urban-N-S

i Stathopoulos-Open-W-E-40m

$\bullet$ Keast-Open-N-S

$\approx$ Stathopoulos-Open-N-S-40m

Fig. 11: Comparison of shear coefficients for low-rise and medium-rise buildings in ASCE/SEI 7-10 with experimental results from previous studies. 


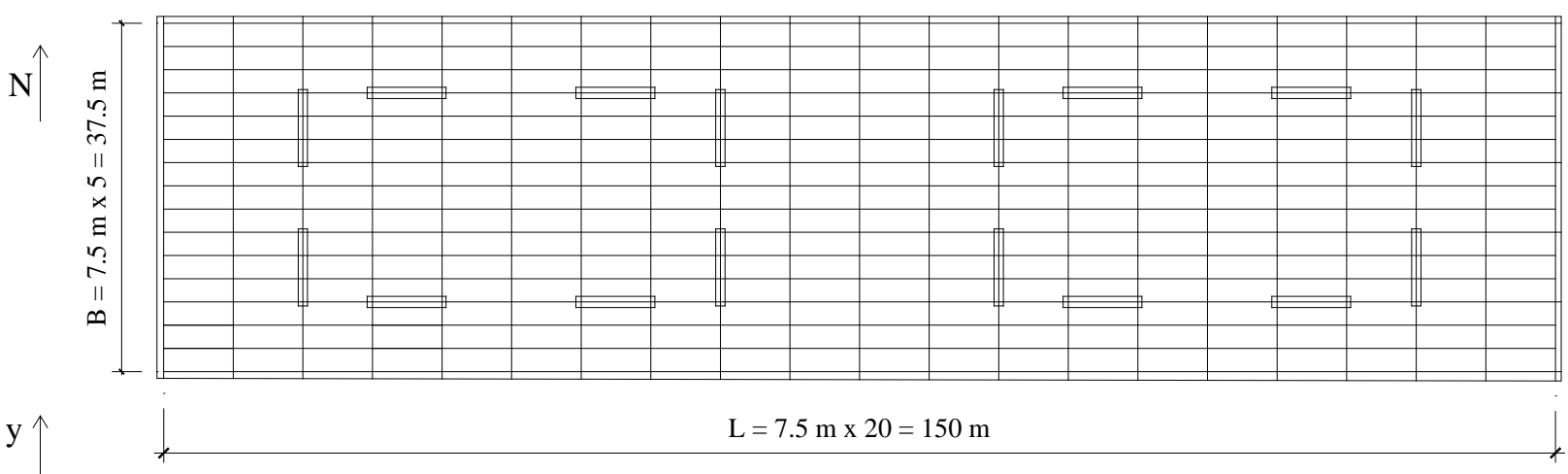

a. Common plan view

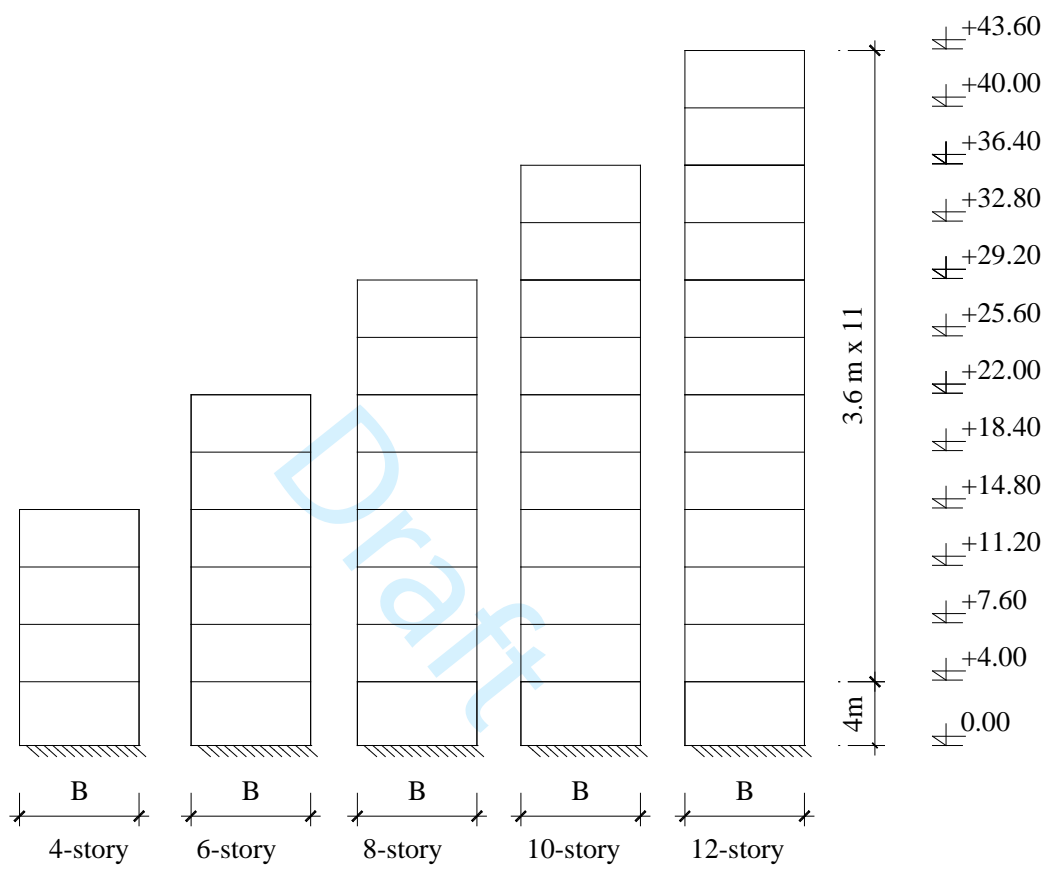

b. Elevation views

Fig. 12: Common plan and elevation views of the buildings in the current study. 



Fig. 13: Shear and torsional coefficients according to NBCC 2015 and ASCE/SEI 7-10. 